\title{
MicroRNA expression profiles from eggs of different qualities associated with post-ovulatory ageing in rainbow trout (Oncorhynchus mykiss)
}

\author{
Hao Ma', Gregory M Weber ${ }^{2}$, Mark A Hostuttler ${ }^{2}$, Hairong Wei ${ }^{3}$, Lei Wang ${ }^{1}$ and Jianbo Yao ${ }^{1 *}$
}

\begin{abstract}
Background: Egg quality is an important aspect in rainbow trout farming. Post-ovulatory aging is one of the most important factors affecting egg quality. MicroRNAs (miRNAs) are the major regulators in various biological processes and their expression profiles could serve as reliable biomarkers for various pathological and physiological conditions. The objective of this study was to identify miRNAs that are associated with egg qualities in rainbow trout using post-ovulatory aged eggs.

Results: Egg samples from females on day 1, day 7, and day 14 post-ovulation (D1PO, D7PO and D14PO), which had the fertilization rates of $91.8 \%, 73.4 \%$ and less than $50 \%$, respectively, were collected and small RNAs isolated from these samples were subjected to deep sequencing using the Illumina platform. The massive sequencing produced 27,342,477, 26,910,438 and 29,185,371 reads from the libraries of D1PO, D7PO and D14PO eggs, respectively. A three-way comparison of the miRNAs indicated that the egg samples shared 392 known and 236 novel miRNAs, and a total of 414, 481, and 470 known and 243, 298, and 296 novel miRNAs were identified from D1PO, D7PO and D14PO eggs, respectively. Four known miRNAs (omy-miR-193b-3p, omy-miR-203c-3p, omy-miR-499-5p and omy-miR-7550-3p) and two novel miRNAs (omy-miR-nov-95-5p and omy-miR-nov-112-5p) showed significantly higher expression in D1PO eggs relative to D14PO eggs as revealed by both deep sequencing and real time quantitative PCR analysis. GO analysis of the predicted target genes of these differentially expressed miRNAs revealed significantly enriched GO terms that are related to stress response, cell death, DNA damage, ATP generation, signal transduction and transcription regulation.

Conclusions: Results indicate that post-ovulatory ageing affects miRNA expression profiles in rainbow trout eggs, which can in turn impact egg quality. Further characterization of the differentially expressed miRNAs and their target genes may provide valuable information on the role of these miRNAs in controlling egg quality, and ultimately lead to the development of biomarkers for prediction of egg quality in rainbow trout.
\end{abstract}

Keywords: microRNA, Egg quality, Post ovulation, Rainbow trout

\section{Background}

Fish egg quality is defined as the capability of an egg to become fertilized and subsequently develop into a normal embryo or the probability of eggs to exhibit low mortalities at fertilization, eyeing, hatching, and first feeding [1]. The production of high quality eggs is a major objective of the aquaculture industry, as egg quality not only affects fertilization rate, but also is an important attribute of

\footnotetext{
* Correspondence: jianbo.yao@mail.wvu.edu

${ }^{1}$ Division of Animal and Nutritional Sciences, West Virginia University, Morgantown, WV 26506, USA

Full list of author information is available at the end of the article
}

robust embryonic development $[2,3]$. However, visible differences between good and bad eggs at oviposition is not usually conspicuous in rainbow trout, and therefore, the inclusion of eggs from individual females with poor egg quality into mass incubation units not only results in unexpected losses in egg production, but also problems associated with the removal of dead eggs and embryos after fertilization and fungi infection in the hatchery [4]. Therefore, enabling evaluation of the egg quality before fertilization is highly desirable in aquaculture production.

In teleost fish, a mature egg is developed through multiple phases, including primary oocyte growth, secondary 
growth including the cortical alveolus stage and vitellogenesis, follicle maturation and ovulation $[5,6]$. The coordinated multiple developmental stages can be affected by many genetic, biological, and environmental factors [3]. It has been reported that the quality of rainbow trout eggs is dependent not only on the genetic characteristics of parents [5], but also the age of female [7], and are susceptible to environmental influences, such as the diet of brood fish [8-12], stress [13-15], photoperiod [16], and the physiochemical conditions of the water [17]. All of these factors make egg quality highly variable and difficult to control $[18,19]$. As the ovulated eggs in reared rainbow trout do not usually oviposit naturally, post-ovulatory aging of the eggs is widely accepted as a common determinant for egg quality [20-22].

The importance to distinguish good and bad quality eggs before fertilization has driven studies on the identification of markers associated with egg quality in rainbow trout. Wojtczak and coworkers found that very poor quality eggs turn water turbid [23]. Egg survival rate has also been associated with aspects of egg composition [20]. The total amount of water imbibed after 30 minute incubation has been recognized as an indicator of egg quality [24]. In addition, molecular markers that are potential indicators of egg quality have also been reported. Such markers include the maternally-derived IGF-I and IGF-II [25], and LVII fragments as well as other proteins identified from the coelomic fluid [26]. Many specific genes that are potentially involved in the regulation of oocyte maturation, egg developmental potential, and embryo survival were identified by microarray and quantitative real time PCR (RT-qPCR) analyses $[3,27,28]$. Although the above studies have attempted to address the critical factors responsible for the observed variability of egg quality, the molecular mechanisms underpinning the regulation of egg quality in rainbow trout remain largely elusive.

Recent advances in epigenetic research have demonstrated that the evolutionarily conserved microRNAs (miRNAs) play important roles in differentiation and maturation of various cell types [29,30]. In zebrafish, mutant embryos lacking mature miRNAs had severe deformity during embryogenesis [31-34]. In mouse, although the miRNA functions are suppressed during oocyte maturation, the maternal miRNAs are critical to normal embryonic development [35-38]. In addition, many miRNAs have been shown to play roles in programmed cell death [38-42]. A comprehensive review of miRNAs in teleost fish development, reproduction and response to environmental stimuli was published recently [43]. In order to identify the miRNAs that might play important roles in oocyte and embryonic development in rainbow trout, the expression of miRNAs in rainbow trout eggs and early embryos have been studied and some novel eggpredominant miRNAs were identified $[44,45]$. In this study, post-ovulatory aged rainbow trout eggs with different qualities were collected and used to generate miRNA transcriptome profiles for identifying specific miRNAs associated with egg quality, which could potentially be used as biomarkers for evaluating egg quality. The study also provides new information and insights for future studies to elucidate the gene regulatory networks involved in the control of egg quality.

\section{Results}

Identification of known and novel miRNAs in eggs of different qualities

Small RNA libraries constructed from eggs of different ages post-ovulation were subjected to deep sequencing using the Illumina platform. The massive sequencing produced 27,342,477, 26,910,438 and 29,185,371 reads from the libraries constructed from D1PO, D7PO and D14PO eggs, respectively (Table 1 ). After removing the impurity sequences, known mRNAs, non-coding RNA families without miRNA, and repetitive DNA sequences, the remaining $23,554,621,26,144,764$ and $28,408,709$ sequences from these three samples were used for identification of known miRNAs and prediction of new miRNAs.

A total of 2,945,228, 2,261,910 and 1,464,754 sequences from D1PO, D7PO and D14PO eggs, respectively, were mapped to miRbase database (Release 21). Based on the criteria described in "Methods" section for known miRNAs, a total of 496 known miRNAs were identified from the three samples (Additional file 1: Table S1). Predication of novel miRNAs was carried out according to the criteria that the extended sequences of the miRNAs at the aligned rainbow trout genomic locations have the propensity of forming hairpin structures, and the sequences do not meet the criteria of known miRNAs. The number of novel miRNAs predicted from our datasets was 306 (Additional file 1: Table S2).

\section{Identification of differentially expressed miRNAs in eggs of different qualities}

A three-way comparison of the miRNAs among the samples indicated that D1PO, D7PO and D14PO eggs shared 392 known and 236 novel miRNAs (Figure 1). A total of 414, 481, and 470 known miRNAs and 243, 298, and 296 novel miRNAs were identified from D1PO, D7PO, and D14PO samples, respectively (Table 2). To identify miRNAs

Table 1 Number of sequences generated from small RNA libraries of eggs with different qualities

\begin{tabular}{llll}
\hline Items & D1PO & D7PO & D14PO \\
\hline Total reads & $27,342,477$ & $26,910,438$ & $29,185,371$ \\
Mappable reads & $23,554,621$ & $26,144,764$ & $28,408,709$ \\
Reads mapped to miRbase & $2,945,228$ & $2,261,910$ & $1,464,754$ \\
Reads for novel miRNA prediction & $13,421,585$ & $14,105,022$ & $15,709,247$ \\
\hline
\end{tabular}




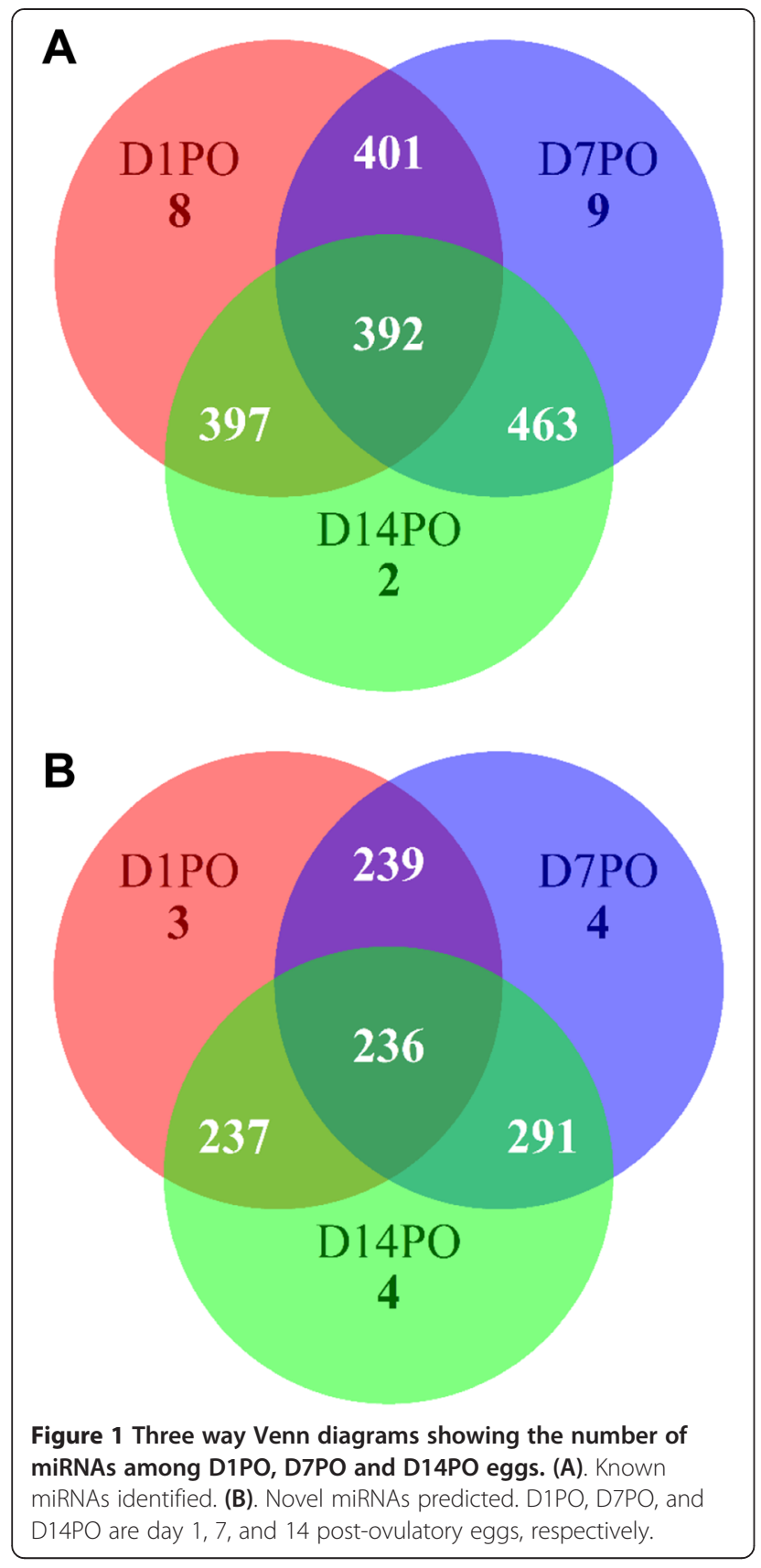

Table 2 Number of known and novel miRNAs identified from eggs of different qualities

\begin{tabular}{llll}
\hline miRNAs & D1PO & D7PO & D14PO \\
\hline Known (total) & 414 & 481 & 470 \\
Novel (total) & 243 & 298 & 296 \\
Known (specific) & 8 & 9 & 2 \\
Novel (specific) & 3 & 4 & 4 \\
\hline
\end{tabular}

that are related to egg quality, the miRNA reads in D1PO and D14PO samples were quantile normalized and compared. A total of 189 miRNAs showed differential expression between the 2 samples (fold change greater than 3). Eighty-eight miRNAs showed higher expression in high quality eggs, while 101 miRNAs displayed higher expression in low quality eggs (Additional file 1: Table S3). Differentially expressed miRNAs with a fold change greater than 10 are shown in Figure 2. Interestingly, the majority of the miRNAs highly expressed in D1PO eggs are known miRNAs (70.45\%), while majority of the miRNAs with higher expression in D14PO eggs are novel miRNAs (64.36\%) (Figure 3).

The differentially expressed miRNAs with a fold change greater than 10 and normalized reads greater than 50 in both samples were subjected to real-time quantitative PCR (RT-qPCR) analysis. Based on melting curve analysis, we selected 7 miRNAs that showed specific amplifications for further analysis (Additional file 2: Figure S1). Six of the 7 miRNAs that were successfully analyzed by RT-qPCR showed significantly higher expression in D1PO vs. D14PO eggs, which is consistent with the deep sequencing results, although the magnitude of fold changes shown by the two methods was not the same (Figure 4). Of the $6 \mathrm{miR}-$ NAs, 4 are known miRNAs (omy-miR-193b-3p, omymiR-203c-3p, omy-miR-499-5p and omy-miR-7550-3p) and 2 are novel miRNAs (omy-miR-nov-95-5p, omymiR-nov-112-5p).

\section{Analysis of predicted targets of the differentially expressed miRNAs}

PITA and miRanda algorithms were used to predict the target genes of the 6 differentially expressed miRNAs that were validated by RT-qPCR analysis, A total of 178 gene entries from gene index database (http://www. animalgenome.org/repository) were predicted, which represent 114 known genes and 23 unknown genes (Additional file 1: Table S3). In addition, when mitochondrial genome was used as a query, a gene encoding cytochrome c oxidase subunit 1 (COX6B1) was predicted as the target of omy-miR-nov-95-5p. GO functional enrichment analysis of the target genes was carried out using Blast2GO software [46]. The results indicated that the top three GO terms (second level) in biological process include cellular process, metabolic process, and single organismal process, and the most significant GO terms in molecular function are binding, catalytic activity, and transporter activity (Figure 5). In comparison with the recent transcriptome data in rainbow trout [47], the significantly enriched $\mathrm{GO}$ terms are single-organism process and membrane. Interestingly, the GO term of cell death, which is one of the indicators of egg quality, is under the children branches of single-organism process. 


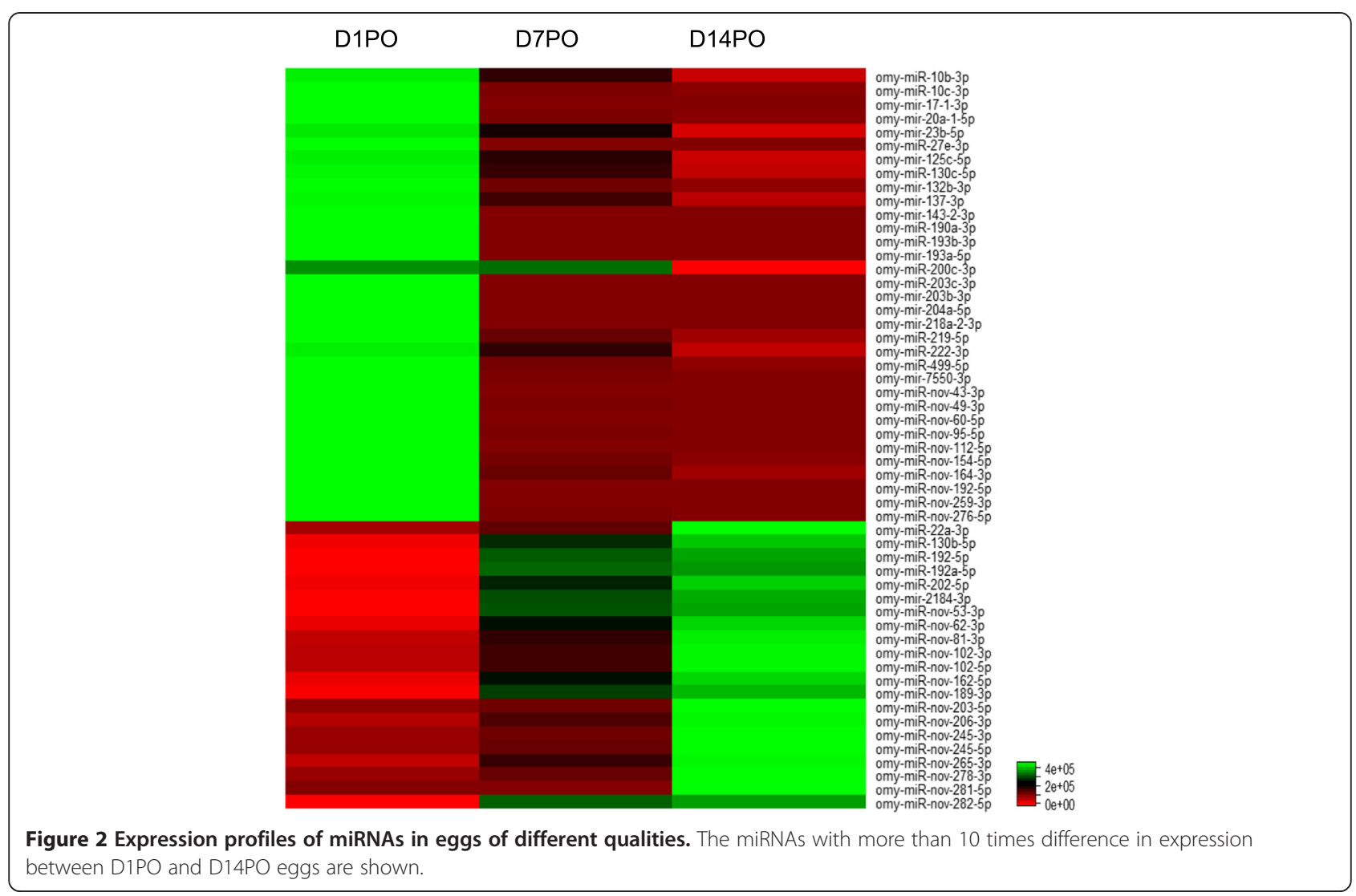

GO enrichment analysis using 96,546 rainbow trout unique transcript sequences as the background showed that 23,23 , and $90 \mathrm{GO}$ terms in cellular component, molecular function, and biological process, respectively, are significantly enriched (Adjusted p-value $<0.05$ ) (Additional file 1: Table S5). The genes associated with the significantly enriched GO terms are mainly involved in response to stress and DNA/RNA damage (RPB4, RECQ4A, CHD1L, WDR61, and CNOT1), cell death and signal transduction (RASSF5, GEM, RAB14, and CACNA1E), energy

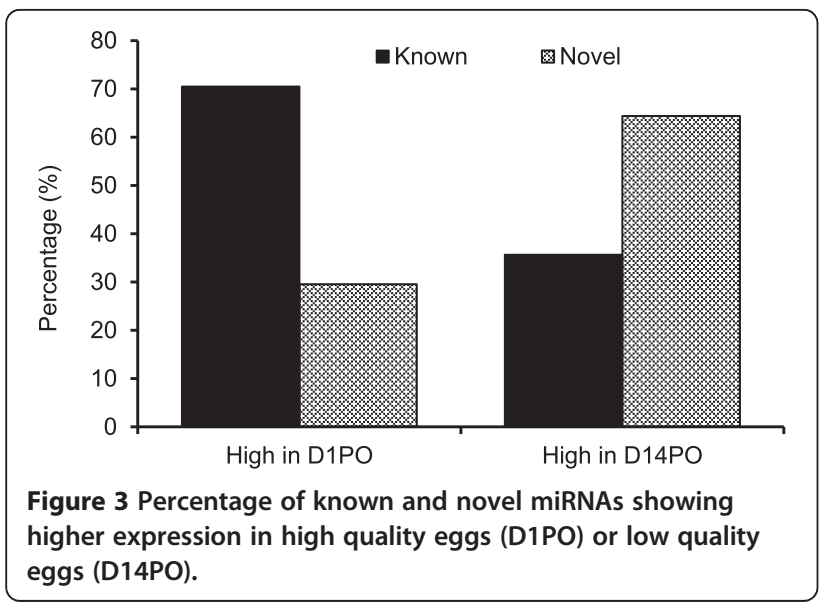

and transcription regulation (ATP5A1, COX6B1, CDT1, GTF2A2, SIX1, and GMEB2).

\section{Discussion}

Using deep sequencing in combination with RT-qPCR, we have identified 6 miRNAs that are associated with egg quality in rainbow trout. These miRNAs could potentially be used as biomarkers for prediction of egg quality in rainbow trout. Our results showed that the numbers of known and novel miRNAs do not show dramatic changes among eggs of different qualities (Table 2), however, most of the highly expressed miRNAs in high quality eggs are known miRNAs and most of the highly expressed miRNAs in low quality eggs are novel miRNAs.

In the study, we used post ovulatory aged eggs with different fertilization rates to identify miRNAs that are associated with egg quality. The D1PO, D7PO and D14PO eggs contained both "good" and "bad" eggs of varying proportions resulting from temporal change of eggs held in the body cavity. Therefore, the miRNAs among these egg samples have only quantitative discrepancy. It is conceivable that identification of evident miRNA expression discrepancy among these samples with varying proportion of "good" and "bad" eggs is challenging, and such difficulties have also been documented in previous studies [25,48]. The SYBR green based RT-qPCR method for miRNA 


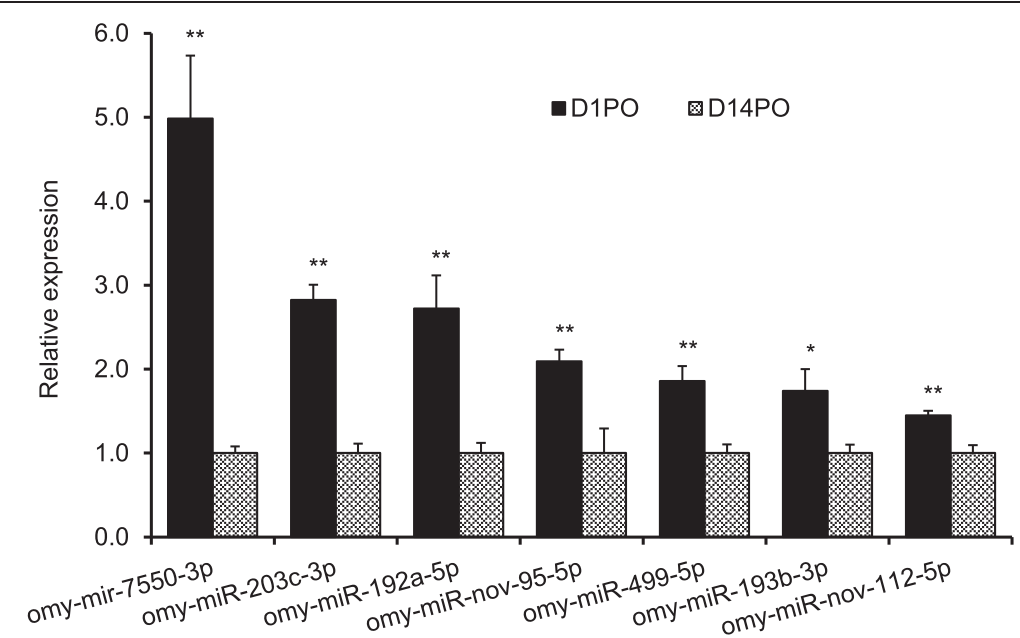

Figure 4 RT-qPCR validation of differentially expressed miRNAs identified by deep sequencing between D1PO and D14PO eggs. Data were normalized using $\beta$-actin and $18 \mathrm{~S}$ rRNA. The means of the normalized miRNA expression values ( $n=4$ pools) were calculated and expressed as relative fold changes. Only omy-miR-192a-5p does not match the sequencing data.

detection has its limitations. As both the universal primer and the miRNA specific primer are fixed, it makes optimization of the assay very difficult. Only 7 miRNAs showed specific amplification based on melting curve analysis and many more did not show specific amplifications, although different annealing temperatures were tried.

Mitochondrion is not only vital in ATP generation and maintenance of cell homeostasis, but also central in the apoptotic signaling pathways [49]. It has been reported that some miRNAs were involved in the regulation of mitochondrion-mediated apoptosis [50,51]. In this study, one of the differentially expressed novel miRNAs, omymiR-nov-95-5p, was predicted to target mitochondrial gene $(C O X 6 B 1)$. COX6B1 is known to catalyze the electron transfer from reduced cytochrome $\mathrm{c}$ to oxygen in respiratory chain, and deficiency of cytochrome c oxidase is linked to many human diseases [52]. Therefore, downregulated expression of omy-miR-nov-95-5p in aged eggs may cause abnormal expression of COX6B1, thereby affecting normal mitochondrial respiratory chain and egg quality. In addition, many predicted target genes of omymiR-nov-95-5p and omy-miR-193b-5p are associated with significantly enriched GO terms, which include cell death, stress response, DNA damage and repair, and RNA degradation. These genes include RASSF5, RPB4, RECQ4A, CHD1L, WDR61, and CNOT1. Abnormal expression of these important genes may also contribute to decreased quality of D14PO eggs. Some of the differentially expressed miRNAs identified in this study, such as miR-449 and miR-203, have been reported to affect cell death and tumor suppression [53,54], but the other differentially expressed miRNAs have not been characterized with regard to their functions. Therefore, a comprehensive study of these miRNAs and their target genes would help understanding the factors contributing to egg quality.

Many factors can affect miRNA expression $[41,55]$. In rainbow trout, the eggs kept in the cavity for extended time are associated with reduced levels of IGF I and IGF $I I$, and increased levels of KRT8, CTSZ and other transcripts [25,48]. Increased activities of GOT1, ACPP, LVII fragments and others biomolecules in the coelomic fluid have also been shown to be related to egg quality [22,26]. In addition, the levels of $17 \alpha 20 \beta-\mathrm{P}$ and $17 \alpha-\mathrm{OH}-\mathrm{P}$ in blood vary significantly before and after ovulation [21]. It is not known if these changes may directly or indirectly affect miRNA expression, leading to the changes in target gene expression. Furthermore, some miRNAs have regulatory roles in controlling other miRNAs [56]. Therefore, in order to understand the mechanisms underlying the changes in egg quality such as those associated with post-ovulation aging in rainbow trout, it would be important to systematically study the interaction networks among physiological and environmental factors affecting egg quality, the miRNAs and their target genes.

\section{Conclusions}

This study identified 6 differentially expressed miRNAs that are associated with egg quality in rainbow trout. Further characterization of these miRNAs, especially the novel ones, and their target genes may provide valuable information on the roles of these miRNAs in controlling egg quality, and ultimately lead to the development of novel biomarkers for evaluation of egg quality in rainbow trout. 


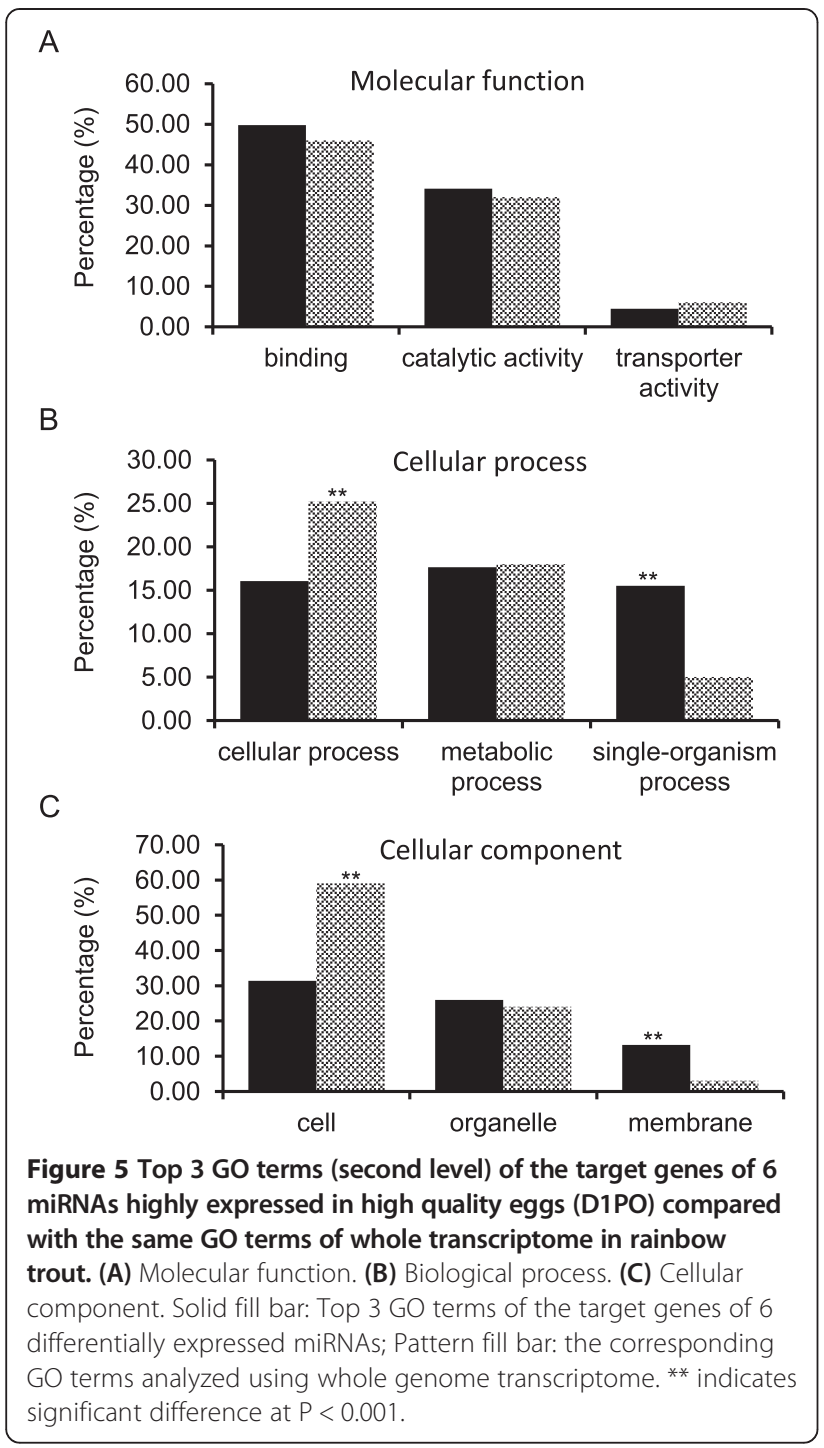

\section{Methods}

\section{Ethics statement}

All experiments were conducted under a protocol approved by the USDA/ARS National Center for Cool and Cold Water Aquaculture Institutional Animal Care and Use Committee (protocol \#70).

\section{Sample collection and determination of fertilization rate} Samples from commercial populations of Troutlodge Inc. (Sumner, WA) were reared for at least two generations using commercial trout feed under the temperature of $12.0-12.5^{\circ} \mathrm{C}$ in treated spring water recirculating partially in the National Center for Cool and Cold Water Aquaculture (Kearneysville, WV). The fish were checked daily for ovulation as described previously [57]. Eggs were collected from 32 females on day 1 , day 7 , and day 14 postovulation (D1PO, D7PO, and D14PO) as described previously $[57,58]$. The eggs for RNA isolation were placed in microcentrifuge tubes and frozen in liquid nitrogen after removal of coelomic fluid, and then stored in $-80^{\circ} \mathrm{C}$ freezer until extraction of RNA.

Eggs fertilized using pooled milt from at least three males were placed in Davidson's solution for microscopic analysis to determine fertilization rate. Fertilization rate was based on cleavage evaluation of 50 embryos per group as described previously $[57,58]$. The fertilization rates for D1PO, D7PO, and D14PO were 91.8\%, 73.4\% and less than $50 \%$, respectively.

\section{Sequencing and analysis of egg miRNAs}

Total RNA from the eggs was isolated using Trizol reagent (Invitrogen, Carlsbad, CA) according to the manufacturer's instructions followed by additional purification steps with lithium chloride precipitation. The RNA integrity was evaluated by gel electrophoresis, and the RNA purity was checked by the ratio of $\mathrm{OD}_{260} / \mathrm{OD}_{280}$. The RNAs isolated from eggs of different females were pooled, and the pooled RNAs were used for sequencing of miRNAs, which was performed on an Illumina GAIIx by LC Sciences (Huston, TX) as described previously [45]. The software package, ACGT101-miR v3.5 from LC Sciences (Houston, TX), was used for analyzing the sequencing data. Sequences with low resolution, copy number less than 10 , length shorter than $15 \mathrm{nt}$ or longer than $26 \mathrm{nt}$, adapter sequences, junk sequences, and simple sequence were filtered out. In addition, the sequences mapped to the databases of mRNA (ftp://ftp.ncbi.nih.gov/ genomes/D_rerio/RNA/Gnomon_mRNA.fsa.gz), Rfam (http://rfam.janelia.org) and Repbase (http://www.girinst. org/repbase) were also removed. The remaining sequences were used to BLAST against all miRNAs in the miRBase database (release 21) to identify known miRNAs (less than 2 mismatches in the first $18 \mathrm{nt}$ or E-values equal or smaller than 0.01) $[59,60]$. The sequences that did not match known miRNAs were mapped to the rainbow trout genome [61] to identify potentially novel miRNAs. Novel miRNAs were predicted if the extended sequences ( $60 \mathrm{nt}$ in both directions) at the aligned positions have the propensity to form hairpin structures as analyzed using RNAfold program.

The reads for each miRNA (either known or novel) were aligned by Clustal analysis using CLC Genome Workbench (CLC bio, MA). Quantile normalization in Limma package was used to normalize the miRNA reads [62]. The difference in miRNA expression between high quality egg (D1PO) and low quality egg (D14PO) was evaluated by Z-test [63].

\section{RT-qPCR analysis of miRNA expression}

Two $\mu \mathrm{g}$ of DNase-treated RNAs (4 pools from D1PO or D7PO or D14PO eggs) were converted to cDNA using 
miScript reverse transcriptase mix (Qiagen, Valencia, CA). The cDNA samples were used for RT-qPCR quantification and melting curve analysis of miRNAs using miRNA specific primers (Additional file 1: Table S6) in combination with the miScript universal primer (Qiagen, Valencia, CA). Rainbow trout $\beta$-actin and 18S rRNA genes were used as endogenous controls. RT-qPCR was performed in duplicate for each cDNA on a Bio-Rad CFX96 system. The iQ ${ }^{\mathrm{mi}}$ SYBR Green Supermix (Bio-Rad, Hercules, CA) was used in $20 \mu \mathrm{l}$ reaction volumes containing $100 \mathrm{nM}$ of each primer and $5 \mu \mathrm{l}$ of 1:150 diluted cDNA. Cycling parameters were $95^{\circ} \mathrm{C}$ for $3 \mathrm{~min}$ followed by 40 cycles of $95^{\circ} \mathrm{C}$ for $10 \mathrm{sec}$ and 50 to $62^{\circ} \mathrm{C}$ for $1 \mathrm{~min}$. Melting curve analyses were programmed following the amplifications. Standard curves for all miRNAs and the endogenous controls were constructed using a serial dilution of a pooled cDNA sample. For each sample, the quantity of the specific miRNAs and the reference genes was determined from respective standard curves. The mean quantity of the specific miRNAs was then divided by the geometric mean of the 2 reference genes to obtain a normalized value. Mean differences in expression levels were reported as relative fold changes using the lower expression value as a calibrator. Differences in miRNA expression were determined by one-way analysis of variance (ANOVA) using $\mathrm{R}$ software.

\section{Identification of miRNA targets via computational analysis} Two miRNA target prediction algorithms, miRanda (http://www.microrna.org/microrna/home.do) [64] and PITA (http://genie.weizmann.ac.il/pubs/mir07/mir07_ exe.html) [65] were used to identify the target genes of the egg quality related miRNAs. Sequences of 15,387 3'UTRs and 14,788 coding regions fetched from rainbow trout transcripts as described previously [45] were used in the analysis. The rainbow trout mitochondrial genome sequence (L29771) was downloaded from the GenBank database [66]. The thresholds of miRanda for candidate target sites were paring score $S \geq 150$ and energy score $\Delta G \leq-18 \mathrm{kcal} / \mathrm{mol}$, where $S$ is the sum of single-residue-pair match scores over the alignment trace and $\Delta G$ is the free energy of duplex formation from a completely dissociated state which was calculated using the Vienna package [64]. The score $\Delta \Delta \mathrm{G} \leq-15.0$ was used for PITA [67].

\section{Gene ontology analysis}

The online software blast2go (http://www.blast2go.com) was used to analyze the target genes of differentially expressed miRNAs. Enrichment of the gene ontology (GO) terms was tested using hypergeometric function as described earlier [68], and the 96,546 rainbow trout unique transcript sequences (http://www.animalgenome. org/repository/aquaculture) were used as background.
Adjusted p-values by Benjamini and Hochberg false discovery rate (FDR) method were used to determine significance of GO enrichment.

\section{Additional files}

Additional file 1: Table S1. Known miRNAs identified from rainbow trout eggs of different quality. Table S2. Novel miRNAs predicted from rainbow trout eggs of different quality. Table S3. Differentially expressed miRNAs in D1PO vs. D14PO eggs (fold change greater than 3). Table S4. The predicted target genes of 6 differentially expressed miRNAs between D1PO and D14PO eggs validated by RT-qPCR analysis. Table S5. Target genes associated with siginificamtly enriched GO terms. Table S6 Primers used to validate differentially expressed miRNAs.

Additional file 2: Figure S1. Melt peak charts of 7 miRNAs showing specific amplifications in RT-qPCR analysis. $\beta$-actin and $18 \mathrm{~S}$ rRNA are endogenous control genes.

\section{Abbreviations}

miRNA: microRNA; RT-qPCR: Real-time quantitative PCR; D1PO: One day post ovulation; ANOVA: Analysis of variance; GO: Gene ontology; 3 'UTR: 3'untranslated region.

\section{Competing interests}

The authors declare that they have no competing interests.

\section{Authors' contributions}

HM designed the experiment, carried out RNA isolation, sequencing data collection, and RT-qPCR analysis, performed bioinformatical and statistical data analysis, and drafted the manuscript. GW conceived the study, tested fertilization rates, and collected samples. $\mathrm{MH}$ tested fertilization rate and collected samples. HW participated in data analysis and provided resources for data analysis. LW helped in data analysis. JY contributed to overall project design and manuscript preparation. All authors read and approved the final manuscript.

\section{Acknowledgements}

This project was supported by the USDA-ARS Cooperative Agreement No. 58-1930-0-059. It is published with the approval of the director of the West Virginia Agricultural and Forestry Experiment Station as scientific paper No. 3235

\section{Author details}

${ }^{1}$ Division of Animal and Nutritional Sciences, West Virginia University, Morgantown, WV 26506, USA. ${ }^{2}$ National Center for Cool and Cold Water Aquaculture, USDA/ARS, Kearneysville, W 25430, USA. ${ }^{3}$ School of Forest Resources and Environmental Science, Michigan Technological University, Houghton, MI 49931, USA.

Received: 15 September 2014 Accepted: 24 February 2015 Published online: 17 March 2015

\section{References}

1. Bromage N, Jones J, Randall C, Thrush M, Davies B, Springate J, et al. Broodstock Management, Fecundity, Egg Quality and the Timing of Egg-Production in the Rainbow-Trout (Oncorhynchus-Mykiss). Aquaculture. 1992;100(1-3):141-66.

2. Bobe J, Labbe C. Egg and sperm quality in fish. Gen Comp Endocrinol. 2010;165(3):535-48.

3. Bonnet E, Fostier A, Bobe J. Microarray-based analysis of fish egg quality after natural or controlled ovulation. BMC Genomics. 2007:8:55.

4. Ciereszko A, Wojtczak M, Dietrich GJ, Kuzminski H, Dobosz S. A lack of consistent relationship between distribution of lipid droplets and egg quality in hatchery-raised rainbow trout, Oncorhynchus mykiss. Aquaculture. 2009;289(1-2):150-3.

5. Brooks S, Tyler CR, Sumpter JP. Egg quality in fish: what makes a good egg? Rev Fish Biol Fish. 1997;7(4):387-416. 
6. Tyler CR, Sumpter JP. Oocyte growth and development in teleosts. Rev Fish Biol Fish. 1996;6(3):287-318.

7. Bromage NR, Cumaranatunga PRT. Egg production in the rainbow trout. In: Muir JF, Roberts RJ, editors. Recent Advances in Aquaculture, vol. 3. London: Croom Helm; 1988. p. 65-138.

8. Crespo D, Planas JV, Bobe J. Lipopolysaccharide administration in preovulatory rainbow trout (Oncorhynchus mykiss) reduces egg quality. Aquaculture. 2010;300(1-4):240-2

9. Blom JH, Dabrowski K. Reproductive Success of Female Rainbow-Trout (Oncorhynchus-Mykiss) in Response to Graded Dietary Ascorbyl Monophosphate Levels. Biol Reprod. 1995;52(5):1073-80.

10. Washburn BS, Frye DJ, Hung SSO, Doroshov SI, Conte FS. Dietary-Effects on Tissue Composition, Oogenesis and the Reproductive-Performance of Female Rainbow-Trout (Oncorhynchus-Mykiss). Aquaculture. 1990;90(2):179-95.

11. Sandnes K, Ulgenes Y, Braekkan OR, Utne F. The Effect of Ascorbic-Acid Supplementation in Brood-Stock Feed on Reproduction of Rainbow-Trout (Salmo-Gairdneri). Aquaculture. 1984;43(1-3):167-77.

12. Palace VP, Werner J. Vitamins $A$ and $E$ in the maternal diet influence egg quality and early life stage development in fish: a review. Sci Mar. 2006;70:41-57

13. Contreras-Sanchez WM, Schreck CB, Fitzpatrick MS, Pereira CB. Effects of stress on the reproductive performance of rainbow trout (Oncorhynchus mykiss). Biol Reprod. 1998;58(2):439-47.

14. Campbell PM, Pottinger TG, Sumpter JP. Stress Reduces the Quality of Gametes Produced by Rainbow-Trout. Biol Reprod. 1992:47(6):1140-50

15. Campbell PM, Pottinger TG, Sumpter JP. Preliminary Evidence That Chronic Confinement Stress Reduces the Quality of Gametes Produced by Brown and Rainbow-Trout. Aquaculture. 1994;120(1-2):151-69.

16. Bonnet $E$, Fostier A, Bobe J. Characterization of rainbow trout egg quality: A case study using four different breeding protocols, with emphasis on the incidence of embryonic malformations. Theriogenology. 2007;67(4):786-94.

17. Hokanson KE, Mccormic JH, Jones BR, Tucker JH. Thermal Requirements for Maturation, Spawning, and Embryo Survival of Brook Trout, Salvelinus-Fontinalis. J Fish Res Board Can. 1973;30(7):975.

18. Aegerter $\mathrm{S}$, Jalabert B. Effects of post-ovulatory oocyte ageing and temperature on egg quality and on the occurrence of triploid fry in rainbow trout, Oncorhynchus mykiss. Aquaculture. 2004;231(1-4):59-71.

19. Su GS, Liljedahl LE, Gall AAE. Genetic and environmental variation of female reproductive traits in rainbow trout (Oncorhynchus mykiss). Aquaculture. 1997;154(2):10.

20. Craik JCA, Harvey SM. Egg Quality in Rainbow-Trout - the Relation between Egg Viability, Selected Aspects of Egg Composition, and Time of Stripping. Aquaculture. 1984;40(2):115-34.

21. Springate JRC, Bromage NR, Elliott JAK, Hudson DL. The Timing of Ovulation and Stripping and Their Effects on the Rates of Fertilization and Survival to Eying, Hatch and Swim-up in the Rainbow-Trout (Salmo-Gairdneri R). Aquaculture. 1984:43(1-3):313-22

22. Lahnsteiner F. Morphological, physiological and biochemical parameters characterizing the over-ripening of rainbow trout eggs. Fish Physiol Biochem. 2000;23(2):107-18.

23. Wojtczak M, Kowalski R, Dobosz S, Goryczko K, Kuzminski H, Glogowski J, et al. Assessment of water turbidity for evaluation of rainbow trout (Oncorhynchus mykiss) egg quality. Aquaculture. 2004;242(1-4):617-24.

24. Lahnsteiner F, Patzner RA. Rainbow trout egg quality determination by the relative weight increase during hardening: a practical standardization. J Appl Ichthyol. 2002;18(1):24-6

25. Aegerter $\mathrm{S}$, Jalabert $B$, Bobe J. mRNA stockpile and egg quality in rainbow trout (Oncorhynchus mykiss). Fish Physiol Biochem. 2003;28(1-4):317-8.

26. Rime H, Guitton N, Pineau C, Bonnet E, Bobe J, Jalabert B. Post-ovulatory ageing and egg quality: a proteomic analysis of rainbow trout coelomic fluid. Reprod Biol Endocrinol. 2004;2:26.

27. Bobe J, Montfort J, Nguyen T, Fostier A. Identification of new participants in the rainbow trout (Oncorhynchus mykiss) oocyte maturation and ovulation processes using cDNA microarrays. Reprod Biol Endocrinol. 2006:4:39.

28. Nagler JJ, Cavileer TD, Stoddard JW, Parsons JE. Maternal mRNA differences in unfertilized rainbow trout (Oncorhynchus mykiss) eggs from batches exhibiting variable embryonic survival. Cybium. 2008;32(2):233.

29. Jima DD, Zhang J, Jacobs C, Richards KL, Dunphy CH, Choi WW, et al. Deep sequencing of the small RNA transcriptome of normal and malignant human B cells identifies hundreds of novel microRNAs. Blood. 2010;116(23):e118-27.
30. Takacs CM, Giraldez AJ. MicroRNAs as genetic sculptors: Fishing for clues. Semin Cell Dev Biol. 2010;21(7):760-7.

31. Wienholds E, Koudijs MJ, Van Eeden FJM, Cuppen E, Plasterk RHA. The microRNA-producing enzyme Dicer1 is essential for zebrafish development. Nat Genet. 2003;35(3):12

32. Giraldez AJ, Cinalli RM, Glasner ME, Enright AJ, Thomson JM, Baskerville S, et al. MicroRNAs regulate brain morphogenesis in zebrafish. Science. 2005:308(5723):833-8.

33. Giraldez AJ, Mishima Y, Rihel J, Grocock RJ, Van Dongen S, Inoue K, et al. Zebrafish MiR-430 promotes deadenylation and clearance of maternal mRNAs. Science. 2006;312(5770):75-9.

34. Schier AF, Giraldez AJ. MicroRNA function and mechanism: insights from zebra fish. Cold Spring Harb Symp Quant Biol. 2006;71:195-203.

35. Ma J, Flemr M, Stein P, Berninger $P$, Malik R, Zavolan M, et al. MicroRNA Activity Is Suppressed in Mouse Oocytes. Curr Biol. 2010;20(3):265-70.

36. Suh N, Baehner L, Moltzahn F, Melton C, Shenoy A, Chen J, et al. MicroRNA Function Is Globally Suppressed in Mouse Oocytes and Early Embryos. Curr Biol. 2010;20(3):271-7.

37. Tang F, Kaneda M, O'Carroll D, Hajkova P, Barton SC, Sun YA, et al. Maternal microRNAs are essential for mouse zygotic development. Gene Dev. 2007:21(6):644-8.

38. Medeiros LA, Dennis LM, Gill ME, Houbaviy H, Markoulaki S, Fu D, et al. Mir-290-295 deficiency in mice results in partially penetrant embryonic lethality and germ cell defects. Proc Natl Acad Sci U S A. 2011;108(34):14163-8.

39. Farazi TA, Spitzer Jl, Morozov P, Tuschl T. miRNAs in human cancer. J Pathol. 2011;223(2):102-15.

40. Xu P, Guo M, Hay BA. MicroRNAs and the regulation of cell death. Trends Genet. 2004:20(12):617-24.

41. Kulshreshtha R, Davuluri RV, Calin GA, Ivan M. A microRNA component of the hypoxic response. Cell Death Differ. 2008;15(4):667-71.

42. Sachdeva M, Mo YY. miR-145-mediated suppression of cell growth, invasion and metastasis. Am J Transl Res. 2010;2(2):170-80.

43. Bizuayehu TT, Babiak I. MicroRNA in teleost fish. Genome Biol Evol. 2014;6(8):1911-37.

44. Ramachandra RK, Salem M, Gahr S, Rexroad CE, Yao J. Cloning and characterization of microRNAs from rainbow trout (Oncorhynchus mykiss): Their expression during early embryonic development. BMC Dev Biol. 2008;8:41.

45. Ma H, Hostuttler M, Wei H, Rexroad 3rd CE, Yao J. Characterization of the Rainbow Trout Egg MicroRNA Transcriptome. PLoS One. 2012;7(6):e39649.

46. Gotz S, Garcia-Gomez JM, Terol J, Williams TD, Nagaraj SH, Nueda MJ, et al. High-throughput functional annotation and data mining with the Blast2GO suite. Nucleic Acids Res. 2008;36(10):3420-35.

47. Salem M, Rexroad CE, Wang JN, Thorgaard GH, Yao JB. Characterization of the rainbow trout transcriptome using Sanger and 454-pyrosequencing approaches. BMC Genomics. 2010;11:564.

48. Aegerter $\mathrm{S}$, Jalabert $\mathrm{B}$, Bobe J. Large scale real-time PCR analysis of mRNA abundance in rainbow trout eggs in relationship with egg quality and post-ovulatory ageing. Mol Reprod Dev. 2005;72(3):377-85.

49. Suen DF, Norris KL, Youle RJ. Mitochondrial dynamics and apoptosis. Genes Dev. 2008;22(12):1577-90.

50. Gao P, Tchernyshyov I, Chang TC, Lee YS, Kita K, Ochi T, et al. c-Myc suppression of miR-23a/b enhances mitochondrial glutaminase expression and glutamine metabolism. Nature. 2009;458(7239):762-5. U100.

51. Nakagawa $Y$, linuma M, Naoe T, Nozawa Y, Akao Y. Characterized mechanism of alpha-mangostin-induced cell death: Caspase-independent apoptosis with release of endonuclease-G from mitochondria and increased miR-143 expression in human colorectal cancer DLD-1 cells. Bioorg Med Chem. 2007:15(16):5620-8

52. Lazarou M, Smith SM, Thorburn DR, Ryan MT, McKenzie M. Assembly of nuclear DNA-encoded subunits into mitochondrial complex IV, and their preferential integration into supercomplex forms in patient mitochondria. FEBS J. 2009;276(22):6701-13.

53. Lize M, Klimke A, Dobbelstein M. MicroRNA-449 in cell fate determination. Cell Cycle. 2011;10(17):2874-82

54. Sonkoly E, Lovén J, Xu N, Meisgen F, Wei T, Brodin P, et al. MicroRNA-203 functions as a tumor suppressor in basal cell carcinoma. Oncogenesis. 2012;1(3):e3

55. O'Donnell KA, Wentzel EA, Zeller KI, Dang CV, Mendell JT. c-Myc-regulated microRNAs modulate E2F1 expression. Nature. 2005;435(7043):839-43. 
56. Tang R, Li L, Zhu D, Hou D, Cao T, Gu H, et al. Mouse miRNA-709 directly regulates miRNA-15a/16-1 biogenesis at the posttranscriptional level in the nucleus: evidence for a microRNA hierarchy system. Cell Res. 2012;22:504-15.

57. Weber GM, Hostuttler MA. Factors affecting the first cleavage interval and effects of parental generation on tetraploid production in rainbow trout (Oncorhynchus mykiss). Aquaculture. 2012;344:231-8.

58. Hershberger WK, Hostuttler MA. Variation in time to first cleavage in rainbow trout Oncorhynchus mykiss embryos: A major factor in induction of tetraploids. J World Aquacult Soc. 2005;36(1):96-102.

59. Buchold GM, Coarfa C, Kim J, Milosavljevic A, Gunaratne PH, Matzuk MM. Analysis of microRNA expression in the prepubertal testis. PLoS One. 2010;5(12):e15317.

60. Griffiths-Jones S. miRBase: microRNA sequences and annotation. Curr Protoc Bioinformatics. 2010; Chapter 12:Unit 1219 11-10. doi:10.1002/0471250953. bi1209s29.

61. Berthelot C, Brunet F, Chalopin D, Juanchich A, Bernard M, Noel B, et al. The rainbow trout genome provides novel insights into evolution after whole-genome duplication in vertebrates. Nat Commun. 2014;5:3657.

62. Garmire LX, Subramaniam S. Evaluation of normalization methods in mammalian microRNA-Seq data. RNA. 2012;18(6):1279-88.

63. Kal AJ, van Zonneveld AJ, Benes V, van den Berg M, Koerkamp MG, Albermann $\mathrm{K}$, et al. Dynamics of gene expression revealed by comparison of serial analysis of gene expression transcript profiles from yeast grown on two different carbon sources. Mol Biol Cell. 1999;10(6):1859-72.

64. Enright AJ, John B, Gaul U, Tuschl T, Sander C, Marks DS. MicroRNA targets in Drosophila. Genome Biol. 2003;5(1):R1.

65. Kertesz M, lovino N, Unnerstall U, Gaul U, Segal E. The role of site accessibility in microRNA target recognition. Nat Genet. 2007;39(10):1278-84

66. Zardoya R, GarridoPertierra A, Bautista JM. The complete nucleotide sequence of the mitochondrial DNA genome of the rainbow trout, Oncorhynchus mykiss. J Mol Evol. 1995;41(6):942-51.

67. Betel D, Koppal A, Agius P, Sander C, Leslie C. Comprehensive modeling of microRNA targets predicts functional non-conserved and non-canonical sites. Genome Biol. 2010;11(8):R90

68. Wei HR, Yordanov YS, Georgieva T, Li X, Busov V. Nitrogen deprivation promotes Populus root growth through global transcriptome reprogramming and activation of hierarchical genetic networks. New Phytol. 2013;200(2):483-97.

\section{Submit your next manuscript to BioMed Central and take full advantage of:}

- Convenient online submission

- Thorough peer review

- No space constraints or color figure charges

- Immediate publication on acceptance

- Inclusion in PubMed, CAS, Scopus and Google Scholar

- Research which is freely available for redistribution

Submit your manuscript at www.biomedcentral.com/submit 